\title{
COMPARATIVE STUDY BETWEEN OUTCOME OF EARLY AND CONVENTIONAL CATHETER REMOVALAFTER TRANSURETHRAL RESECTION OF PROSTATE
}

\author{
MOHAMMAD MAHFUZUR RAHMAN ${ }^{1}$, SUDIP DAS GUPTA ${ }^{1}$, NAZRUL ISLAM MRIDHA ${ }^{1}$, MAN WAHID $^{1}$, \\ FARHANA BEGUM ${ }^{2}$
}

${ }^{1}$ Department of Urology, Sir Salimullah Medical College, Dhaka, Bangladesh, ${ }^{2}$ Department of Anatomy, SSMC, Dhaka

\begin{abstract}
Objectives: To compare the effect of early and conventional catheter removal after TURP.

Methods: The cases were selected from the admitted patients with BPH by using simple purposive sampling technique. Sixty (60) cases were included in the study fulfilling selection criteria of the patient and numbered chronologically according to their data and time of operation. Odd numbers of cases were included in group- $A(n=30)$ for early catheter removal within 48 hours and even numbers of cases in group- $B(n=30)$ for conventional catheter removal within 3-5 days.
\end{abstract}

Results: Postoperative hospital stay $47.12( \pm 7.92)$ hours in group A and 113.23( \pm 10.8$)$ hours were in group $B(p<0.001)$ that was statistically highly significant.

Conclusion: Early catheter removal within 48 hours following Transurethral Resection of Prostate (TURP) is safe. It reduces the catheter related morbidity and postoperative hospital stay.

Key words: TURP, BPH, Hospital stay, Color of effluent.

Bangladesh J. Urol. 2017; 20(2): 82-86

\section{Introduction:}

Benign Prostatic Hyperplasia (BPH) is the most common disease in male and its incidence is age related. Prevalence of $\mathrm{BPH}$ is $88 \%$ in 80 years and reaching nearly $100 \%$ in 90 years of age 1 .

$\mathrm{BPH}$ conveys its morbidity through lower urinary tract symptoms (LUTS) and complications such as acute urinary retention, obstructive uropathy, urinary tract infections, renal insufficiency. To prevent complications intervention is necessary. Although the management of $\mathrm{BPH}$ has been dramatically modified during the past decade, transurethral resection of prostate (TURP) remains the gold standard ${ }^{2}$.

In recent years issues of cost, morbidity and complications have lead to the development of new surgical treatment modalities such as transurethral needle ablation, microwave thermotherapy, laser ablation and vaporization ${ }^{3}$. Conventional catheterization period (3-5 days) after TURP and prolong hospital stay is an obstacle, as patient cannot be able to resume his normal life early. Length of hospital stay after TURP due to prolong post operative catheterization is considered to be cost disadvantage when compared with new treatment methods. These disadvantage can be overcome by means of early catheter removal ( $<48$ hours) after TURP when it is appropriate and safe ${ }^{4,5}$.

Conventionally it is practiced among the urologist to remove the catheter following TURP from 3rd to 5th POD. However, in recent years a policy of early catheter removal has arisen. Catheter removed on $2^{\text {nd }} P O D, 1^{\text {st }} P O D$ and day case TURP have been found to be safe and effective in selected patients ${ }^{4,6}$. In Bangladesh, continuous debate has been going on among the Urologists about post TURP catheterization period. This study has been designed to compare the result of catheter removal within 48 hours and conventional catheter removal (3-5 days) following TURP.

\section{Methods:}

A hospital based quasi-experimental study was conducted in the Department of Urology of Sir Salimullah

Correspondences: Dr. Mohammad Mahfuzur Rahman, Department of Urology, Sir Salimullah Medical College, Dhaka, Bangladesh. 
Medical College Mitford Hospital Dhaka from October 2012 to March 2014, on patient with bladder outlet obstruction due to benign prostatic hyperplasia (BPH) managed by transurethral resection of prostate (TURP). The cases were selected from the admitted patients with $\mathrm{BPH}$ by using simple purposive sampling technique. Sixty (60) cases were included in the study fulfilling selection criteria of the patient and numbered chronologically according to their data and time of operation. Odd number of cases were included in group$A(n=30)$ for early catheter removal within 48 hours and even numbers of cases in group- $B(n=30)$ for conventional catheter removal within 3-5 days

All patient were evaluated by history, physical examination including DRE, IPSS Score (in non catheterized patients), urine- R/M/E \& C/S, serum electrolytes, serum creatinine, serum PSA, USG of KUB and prostate with MCC and PVR, uroflowmetry, RBS, CXR, ECG with Echocardiography-2D in selected cases, blood grouping and Rh-typing with screening \& cross matching. Patients with documented UTI were treated with appropriate antibiotic and became culture negative before surgery.

Prophylactic injectable antibiotic was given according to urine $\mathrm{C} / \mathrm{S}$ just before induction of anaesthesia. After urethrocystoscopic evaluation TURP was done by Nesbit technique. A 26 Fr. Resectoscope with continuous sheath (Storz) was used during TURP and $1.5 \%$ W/V Glycine were used as irrigation solution during procedure in all cases.
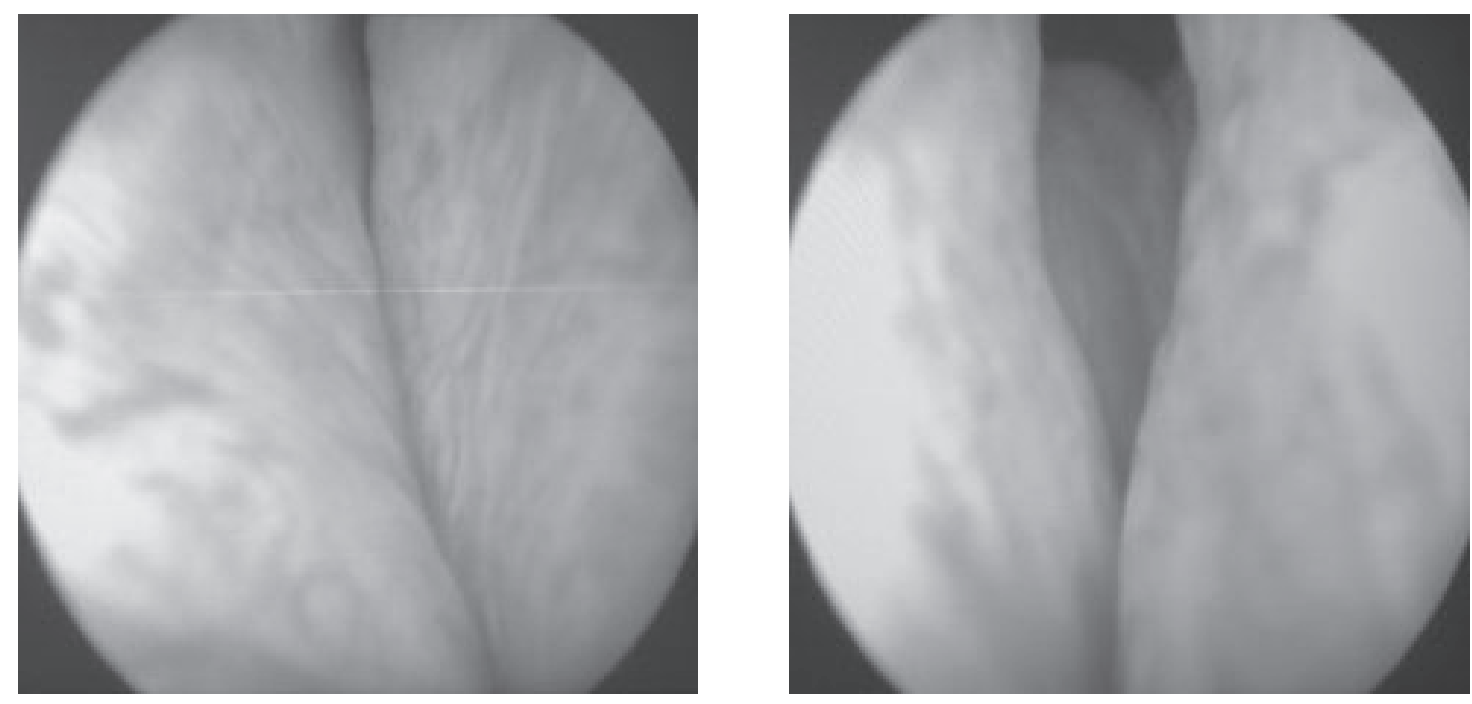

Fig.-1: Urethro-cystoscopic view of BPH
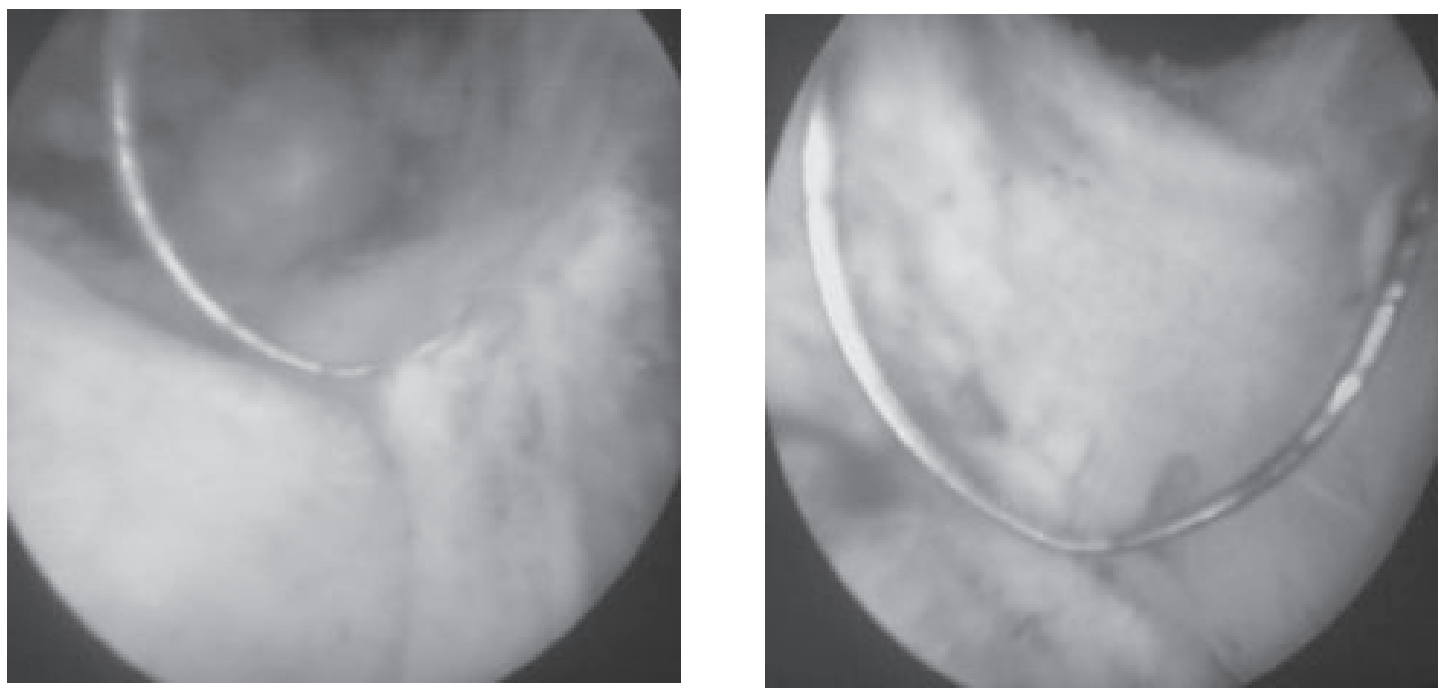

Fig.-2: Endoscopic view of resection of prostate and haemostasis during resection of prostate. 
Table I

Comparisons of postoperative hospital stay between groups

\begin{tabular}{lccc}
\hline \multirow{2}{*}{ Variables } & \multicolumn{2}{c}{ Study group } & P \\
\cline { 2 - 3 } & Group A & value \\
& Mean \pm SD & Mean \pm SD & \\
\hline Postoperative hospital stay (hours) & $47.12( \pm 7.92)$ & $113.23( \pm 10.8)$ & $<0.001$ \\
\hline
\end{tabular}

$P$ value measured by unpaired ' $t$ ' test

At the end of resection, interior of the prostate was inspected thoroughly and all bleeding vessels were coagulated and haemostasis was ensured.

Operation was completed if color of effluent was almost clear or faint pink and water test was good. A $22 \mathrm{Fr}$. Trichannel urethral Foley catheter was introduced into bladder and its balloon was inflated with $40-60 \mathrm{ml}$ distilled water. Continuous bladder irrigation started immediately with normal saline. Catheter traction was applied for 6 hours.

In the post-operative period all patients were monitored closely for vital parameters, color of catheter effluent to asses degree of hematuria, clot retention and transurethral resection syndrome. Patient resume a normal diet and ambulated as soon as recovered from anaesthesia. Patients were given a stool softener and cautioned to avoid straining at defecation.

Criteria for catheter removal included normal vital signs. Adequate urine output, absence of clots, the color of catheter effluent (clear) and physical status which permits independent voiding. In immediate postoperative period (within 6 hours) who met the criteria for catheter removal irrigation was decreased at $10 \mathrm{drops} / \mathrm{min}$ and urethral catheter was removed within 48 hours in groupA and within 3-5 days in group-B after TURP. In all patients urine sample was collected for culture and sensitivity just before catheter removal. Most of the patients were discharged with advice after they could pass urine freely and with a good stream of 2-3 times. Discharge was delayed until the next day if there is any complication such as voiding difficulties, fever or if the urine is unexpectedly bloody.

All cases were followed up at 14th POD and at 1 month for further clinical evaluation. During postoperative period every patient was instructed to report in urology ward if there is any bleeding, urinary retention, and fever after discharge from hospital.

\section{Results:}

A total of 60 cases of benign enlargement of prostate patients were selected for the purpose of the study. All of them were treated with TURP and 30 patients catheter was removed within 48 hours in Group-A and 30 patients catheter was removed conventionally 3-5 days in Group- $B$.

No statistically significant difference found regarding age, weight of prostate, resection time, weight of resected prostatic tissue, preoperative UTI, IPSS, PVR and Qmax as well as postoperative hematuria, urinary retention and UTI after catheter removal.

Postoperative hospital stay $47.12( \pm 7.92)$ hours in group $A$ and $113.23( \pm 10.8)$ hours were in group $B(p<0.001)$ that was statistically highly significant.

Postoperative IPSS, PVR and Qmax after catheter removal were improved significantly in both groups in $14^{\text {th }}$ POD and 1 month after operation. But there was no statistically significant difference among the groups.

\section{Discussion:}

TURP is the gold standard for management of $\mathrm{BPH}^{2}$. Although there is nearly $100 \%$ consensus amongst urologists on the necessity of using a foley catheter, we are not unanimous in identifying when the catheter should be removed. The most important parameters in determining the time of catheter removal are normal vital signs, adequate urine output, absence of clot and acceptable character of the catheter effluent ${ }^{4}$.

In this study mean age $68.59( \pm 5.67)$ yrs were in group $A$ and $69.56( \pm 4.86)$ yrs were in group B. It is similar to the age group mentioned by Agarwal SK et al. (1995) where mean age was $69.9 \mathrm{yrs}$.

In present study comparison of the mean weight of the prostate between two groups, $45.6( \pm 12.75) \mathrm{gm}$ were in group $A$ and $44.7( \pm 11.83)$ gm were in group $B(p>0.05)$ that was not statistically significant. Compared with Chalise PR et al. (2010) study mean weight of the prostate $44.4( \pm 14.5) \mathrm{gm}$ in group I and $44.3( \pm 13.6) \mathrm{gm}$ 
in group II ( $p>0.05)$ that was not statistically significant. That result is similar to my study.

In this study mean resection time of the prostate 58.3 $( \pm 11.48)$ min were group A and $56.7( \pm 10.83)$ min were in group $B(p>0.05)$ that was not statistically significant. Approximately similar result was found in Chalise PR et al. (2010)

In present study mean weight of resected prostatic tissue $34.82( \pm 3.92)$ gm were in group $A$ and $33.67( \pm 4.23) \mathrm{gm}$ were in group $B(p>0.05)$ that was not statistically significant. In a study carried out by Nakagawa and Toguri (2006), $(15.5 \pm 11.0$ vs.18.9 $\pm 15.0 \mathrm{~g}, \mathrm{p}=$ 0.230 ). That result is dissimilar in our study. As the prostate was smaller in size and weight of prostate were less than that of my study.

In present study preoperative urinary tract infection was $09(30 \%)$ in group $A$ and $10(33.3 \%)$ in group $B(p>0.05)$ that was not statistically significant. Agarwal \& Kumar (1993) performed a prospective study on 83 patients among them pre-operative urinary infection observed which was similar to my study.

In present study preoperatively 8 patients had no indwelling catheter in each group. Mean IPSS 30.12 $( \pm 2.92)$ was in group $A$ and $31.23( \pm 2.80)$ in group $B$ $(p>0.05)$, mean PVR $136.7( \pm 24.18) \mathrm{ml}$ were in group $A$ and $138.34( \pm 23.14) \mathrm{ml}$ were in group $B(p>0.05)$ and mean Qmax 08.21 $( \pm 1.52) \mathrm{ml} / \mathrm{sec}$ was in group $A$ and $7.59( \pm 2.13) \mathrm{ml} / \mathrm{sec}$ in group B $(p>0.05)$ that all the parameter were not statistically significant.

In present study post-operative hematuria after catheter removal developed in 05(16.67\%) cases in group A and $04(13.3 \%)$ in group $B(p>0.05)$ that was not statistically significant. Bleeding resolved on conservative management. Similar result was found in Iderpol L. Toscano et al. (2001) studies. All these studies including the present one show that early catheter removal following TURP does not significantly increase the incidence of hematuria.

In present study post-operative urinary retention after catheter removal was present $03(10 \%)$ in group $A$ and $01(3.3 \%)$ in group $B(p>0.05)$ that was not statistically significant. The predominant management of complication in previous studies were reinsertion of the catheter, which was required in $12-14 \%$ of patients in one study by Dodds et al. (1995) and $17.5 \%$ in another by Gordon. Above study including my study show that early catheter removal following TURP does not significant increase the incidence of urinary retention.
In this study post-operative urine culture and sensitivity was done and the culture showed significant bacterial growth (colony count $>1 \mathrm{X} 10^{5} \mathrm{CFU} / \mathrm{ml}$ ) in 14 cases. Among them 06(20\%) was in group A and 08(26.67\%) in group $B(p>0.05)$ that was not statistically significant. In study of Nakagawa and Toguri (2006) the rate of UTI was not significantly different between the groups (1.2 vs. $6.3 \%, p=0.547)$. Higher incidence in present study compared to other studies may be due to improper sterilization of instruments, operation theater and postoperative ward, hospital acquired infections, severe preoperative UTI and pre-operative indwelling catheter for prolong period.

In present study comparison of post-operative hospital stay between two groups, $47.12( \pm 7.92)$ hours in group $A$ and $113.23( \pm 10.8)$ hours was in group $B(p<0.001)$ that was statistically highly significant which could be translated into a reduction in hospital cost. Nakagawa and Toguri (2006) study found mean length of stay after TURP was $1.4 \pm 1.0$ days for the early removal group and $6.2 \pm 3.3$ days for the late removal group $(p<0.001)$. In Mamo and Cohen (1991) study following TURP average post-operative hospital stay in group I (early catheter removal) was 2.86 days and that in group II (conventional catheter removal) was 4.23 days $(p<0.001)$. Early catheter removal didn't increase in morbidity in all studies including my study.

In this study all patient were followed up on $14^{\text {th }} P O D$ shows that mean IPSS, mean PVR and mean Qmax in group A were 08.24 $\pm 1.42,25.48 \pm 3.18 \mathrm{ml} \& 16.11 \pm 1.72$ $\mathrm{ml} / \mathrm{sec}$ respectively and in group $B 7.95 \pm 1.80$, $24.45 \pm 4.14 \mathrm{ml}$ and $17.84 \pm 2.43 \mathrm{ml} / \mathrm{sec}$ respectively and $(p>0.05)$ that all difference were not statistically significant. Similar result was found in Chander et al. (2003) study. In current study also showed no significant difference in IPSS, PVR and Qmax between groups at 1 month.

\section{Conclusion:}

Early catheter removal within 48 hours following Transurethral Resection of Prostate (TURP) is safe, reduces the catheter related morbidity and postoperative hospital stay.

\section{References}

1. Roehrborn CG. (2012) Benign prostatic hyperplasia: Etiology, pathophysiology, epidemiology and Natural history, In: Wein AJ, Kavoussi LR, Novick AC, Partin AW, Peters C.A. Campbell-Walsh's Urology. $10^{\text {th }}$ edition. Philadelphia, Pa: Saunders Elsevier; 2571- 2610. 
2. Kacker R \& Williams SB (2011) Endourologic procedures for benign prostatic hyperplasia: review of indications and outcomes; Urol J, 8(3): 171-6.

3. Fitzpatrick JM. (2012) Minimally invasive and endoscopic management of Benign Prostatic Hyperplasia, In: Wein AJ, Kavoussi LR, NovickAC, Partin AW, Peters CA. Campbell- Walsh's Urology. 10th ed. Philadelphia, Pa: Saunders Elsevier; 2655-94.

4. Aslan G, Celebi I, Arslan D, Esen AA. (2002) Early catheter removal following transurethral prostatectomy: overnight catheterization; Urol Int, 68, 105-108.

5. Feldstein MS \& Benson NA. (1988) Early catheter removal and reduced length of hospital stay following transurethral prostatectomy: a prospective analysis of 100 consecutive patients; $J$ Urol, 140: 532-534.

6. Mueller EJ, Zeidmann EJ, Desmond PM, Thompson IM, Optenberg SA \& Wasson J. (2003) Reduction of length of stay and cost of transurethral resection of the prostate by early catheter removal; Br J Urol, 78, 893-896.

7. Agarwal SK \& Kumar AS. (1993) Early removal of catheter following transurethral resection of the prostate; $\mathrm{Br} J$ Urol, 72, 928-9.
8. Chalise PR, Agarwal CS \& Pandit RK. (2010) Reduction of length of hospital stay after transurethral resection of prostate by early catheter removal: A retrospective analysis; J Urol, 107, 131138.

9. Nakagawa T \& Toguri AG. (2006) Early catheter removal following transurethral prostatectomy: A study of 431 patients; Med Princ Pract 15, 126130.

10. Iderpol L, Toscano JR, Maciel LC, Martins FG, Fernandes AR, Mello MF. (2001) Transurethral resection of the prostate: Prospective Randomized study of catheter removal after 24 hours or 48 hours following surgery; Braz J Urol, 27, 144-147.

11. Dodds L, Lawson PS, Crosthwaite AH \& Wells GR. (1995) Early catheter removal. A prospective study of 100 consecutive patients undergoing transurethral resection of the prostate; $\mathrm{Br} J$ Urol, $75,755-7$.

12. Mamo GJ, \& Cohen SP. (1991) Early catheter removal versus conventional practice in patients undergoing transurethral resection of prostate; $J$ Urology, 37: 519-22.

13. Chander J, Vanitha V, Lal P \& Ramteke VK. (1992) Transurethral resection of the prostate as catheterfree day-care surgery; Br J Urol. 92, 422-425. 